\section{Relationship of Shoot Dieback in Pecan to Fungi and Fruiting Stress}

\author{
Charles C. Reilly and Bruce W. Wood ${ }^{2,4}$ \\ USDA-ARS, Southeastern Fruit and Tree Nut Research, Laboratory, 21 \\ Dunbar Road, Byron, GA 31008
}

\author{
Katherine L. Stevenson ${ }^{3}$ \\ Department of Plant Pathology, University of Georgia, Tifton, GA 31793
}

Additional index words. Carya illinoinensis, Botryosphaeria spp, winter cold injury, stress pathogen, summer dieback

\begin{abstract}
Two shoot dieback maladies (SDM) of pecan [Carya illinoinensis (Wangenh.) C. Koch] are of unknown cause and can adversely affect tree canopy health. They occur during either early spring (SpSDM) or early summer (SuSDM). Field studies found that both maladies predominantly occur on shoots retaining peduncles from the previous crop year's fruit cluster. Isolations of transition zone (from living to dead) tissue of symptomatic shoots, of 14 cultivars, found Phomopsis sp. in $89 \%$ or greater of samples and Botryosphaeria spp. in $\mathbf{4 0 \%}$ or greater of sampled shoots. Isolations occasionally found some combination of eight other apparently saprobic fungal genera with individual genera typically present in $\mathbf{1 0 \%}$ or less of symptomatic shoots but were always present in association with either Phomopsis sp. or Botryosphaeria spp. when shoots exhibited either SuSDM or SpSDM. The SpSDM form was associated with $10 \mathrm{~cm}$ or less of the shoot's length before budbreak in early March before expanding to $30 \mathrm{~cm}$ or greater by late June to produce the SuSDM form, thus, providing evidence for an ongoing and expanding infection common to both SDM forms. The incidence of both "Phomopsis-associated" SDM forms was greatest on trees likely exhibiting substantial stress, some of which was crop-associated. The consistent association of these two fungi with SDM indicates a role for one or both in its development; however, further pathogenicity research is needed to determine if they are the primary cause of these shoot dieback maladies and how they interact with stress factors. Linkage of Phomopsis sp., and possibly Botryosphaeria spp., to these two SDMs raises the possibility of significant canopy damage in prolific cultivars and emphasizes the importance of management practices that minimize stress in orchard trees.
\end{abstract}

Individual bearing pecan [Carya illinoinensis (Wangenh.) C. Koch] trees periodically exhibit episodes of substantial shoot and small limb death referred to here as "shoot dieback maladies" (SDMs). These SDMs have received little study and are not usually considered of economic importance; however, in severe cases, they likely contribute to economic loss of tree canopy structure and photoassimilation capacity. Such loss can potentially influence nutmeat yield, quality, and alternate bearing (Wood, 1995; Worley, 1979a, 1979b). One SDM form occurs during early spring about, and just after, budbreak; as a result, it is here termed "spring shoot dieback malady" (SpSDM). The second SDM form occurs during early summer and is here termed the "summer shoot dieback malady" (SuSDM).

The cause(s) of these maladies are unknown; however, extension specialists and

\footnotetext{
Received for publication 15 Sept. 2009. Accepted for publication 5 Nov. 2009.

${ }^{1}$ Research Plant Pathologist.

${ }^{2}$ Research Horticulturist.

${ }^{3}$ Professor Plant Pathologist.

${ }^{4}$ To whom reprint requests should be addressed; e-mail bruce.wood@ars.usda.gov.
}

by Phomopsis sp. and that severity is influenced by both host genotype and previous tree stress.

\section{Materials and Methods}

Relationship of fungi to shoot dieback forms. SDMs were studied on bearing trees in commercial orchards. Tree age ranged from 12 to $\approx 25$ years. Orchards were managed according to Georgia Extension Service recommendations (Ellis et al., 1991).

In the first study, a survey assessed occurrence of SpSDM on various cultivars and its association with previous-year fruiting. Evaluated cultivars were Cape Fear, Cherokee, Cheyenne, Desirable, Elliott, Mahan, Mohawk, Moneymaker, Moore, Pawnee, Schley, Stuart, Success, Western Schley, and Wichita. Cultivars were randomly sampled in different commercial orchards. One hundred shoots were randomly selected from the lower $4 \mathrm{~m}$ of the tree's canopy during early March before budbreak from each of three trees of each cultivar. Sampled shoots were also measured for necrotic zone length in cases in which shoots exhibited dieback. These same trees were again sampled for symptomatic shoots in early summer (late June) with sampling conducted as described previously but with 50 shoots per tree. Measurements were also made of the length of shoot exhibiting dieback and the age of affected limbs was noted. Sampled shoots were assessed for presence of fungal genera within the narrow transition zone between healthy and dead tissue. Bark, phloem, and xylem cross-sections of shoots were removed, immersed 2 min in sodium hypochlorite $(1.3 \% \mathrm{v} / \mathrm{v})$, rinsed twice with sterile deionized water, placed onto Difco Potato Dextrose Agar (PDA), incubated at $24{ }^{\circ} \mathrm{C}$ under a "12-h:12-h light-dark" period using fluorescent lights, examined after $7 \mathrm{~d}$ for fungi growing from samples, with fungi then identified to genus. As a control, segments of asymptomatic shoot tissue, from shoots of the same cultivar and at the same distance from the apex as the diseased shoots, were sampled in late March, incubated, and fungi assessed as described previously. Symptomatic shoots were examined to rule out damage by stem girdling or boring insects.

In the second study, symptomatic shoots of the 14 cultivars described were studied over two additional growing seasons [late March (SpSDM), before budbreak in Year 1 and 2; late June (SuSDM) in Year 1 and 2] with focus on presence of Phomopsis spp. and Botryosphaeria spp. in the isolations of symptomatic tissue. Procedures were as described previously but without measurement of length of damaged limbs and assessment of the age of dead shoot. Isolation frequencies were derived for comparable tissues in both symptomatic and asymptomatic shoots of all cultivars.

In a third study, symptomatic shoots of nine of the 14 cultivars studied were again assessed for presence of Phomopsis spp. and Botryosphaeria spp. in SuSDM shoots/limbs 
during late August. Procedures were as described in the second study. Isolation frequencies were derived for symptomatic and asymptomatic shoots of trees of each cultivar as described previously.

Relationship to stress. Observations arising from the previously described studies led the authors to postulate that incidence of SpSDM and SuSDM is influenced by tree stress. This influence of stress on incidence of SpSDM was assessed using 12-year-old 'Cherokee' trees spaced on a $9.3 \mathrm{~m} \times 9.3-\mathrm{m}$ square. Two years earlier, trees in the test orchard exhibited high incidence of SpSDM when trees were exposed to a wet spring and early summer and with a heavy crop load. A stressful crop load environment was therefore constructed in the present study in an effort to induce the SpSDM observed previously and to note which fungal pathogens were associated with the malady.

This study tests the hypothesis that degree of tree stress during the previous growing season influences expression of SpSDM. Experimental trees were selected to be uniform in tree size (trunk diameter and crown volume) with blocks based on apparent crop load in late May. Four treatments were constructed to provide four different degrees of potential physiological stress by varying water availability (i.e., "nonirrigated" versus "irrigated") and crop load ("light crop" versus "heavy crop"). The "nonirrigated" treatment received water from only natural rainfall after May (4.32 cm June, 0. 48 cm July, 10.75 $\mathrm{cm}$ August, no rainfall during the fruit-filling period in September and early October). Irrigated trees received additional water at the equivalence of $3 \mathrm{acre} / \mathrm{cm} /$ week for 8 weeks (through solid-set sprinklers positioned $0.5 \mathrm{~m}$ above the orchard floor) from early June until mid-August; thus, soils were relatively moist during the fruit-sizing period and therefore allowed for relatively large fruit, which in turn increased fruit demand for assimilates. Crop load was varied to introduce two fruit associated classes of tree stress-i.e., light (i.e., minimum) versus heavy (i.e., maximum) crop load. The "minimum crop-load" treatment consisted of removing by hand every other fruit cluster (i.e., $\approx 50 \%$ ) uniformly throughout the canopy during the second week of June, just before the log phase of fruit growth. The "maximum crop-load" stress condition arose from retaining $100 \%$ of the natural heavy crop load ( $\approx 70 \%$ to $90 \%$ terminal shoots possessing fruit clusters, depending on block). Thus, trees had a very heavy crop load before imposition of tree stress treatments. Degree of stress was based partially on the amount of kernel mass that the tree would be required to deposit to fully fill nuts (note that nut size varies as a consequence of differences in water availability during the fruit-sizing phase occurring before late August with sufficient water stress conditions causing smaller nuts) and partially based on the magnitude of crop load per tree. The four stress treatments are therefore classified as "severe" (large crop load of large fruit), "moderate" (large crop load of small fruit), "light" (small crop load of large fruit), and "minimal" (small crop load of small fruit).

The experimental design was comprised of four "stress" treatments structured as a randomized complete block (i.e., six) design with single-tree experimental units $(n=24)$. Experimental units were spatially located with a guard tree between irrigated and nonirrigated trees. Treatments produced trees likely experiencing different degrees of stress based on kernel mass needing to be deposited during the filling phase, in September and early October, to have fully filled kernels. Previous-season bearing shoots were assessed the following spring for frequency of SpSDM symptoms exhibited by new terminal shoots after imposition of stress treatments. Frequency was based on selection tree's canopy and the rating of $100 \%$ of the terminal and lateral shoots on that limb for SpSDM. Tissue samples were taken as described previously from symptomatic shoots and the incidence of Phomopsis spp. and other fungal genera determined. Rainfall and temperature data were recorded by a weather station $\approx 0.5 \mathrm{~km}$ from the study site. Data were analyzed by analysis of variance and means separated by Tukey's honestly significant difference test.

\section{Results}

Dieback maladies exhibited by several cultivars. Based on a sampling of 14 cultivars, SpSDM was apparent immediately before, during, and just after budbreak (late March to early to mid-April) in all cultivars (Table 1). Observations revealed that the malady occurred primarily on 1-year-old reproductive shoots, supporting fruit, during the previous growing season, and with little or no incidence on shoots that were vegetative during the previous growing season. The of one major limb on the southern face of the

SpSDM (Fig. 1) extended down the supporting branch as far as $\approx 22$ to $44 \mathrm{~cm}$ and up to as much as 4-year-old wood, by June, to produce symptoms identical to the other shoot dieback malady-SuSDM (Fig. 2). Symptoms just after budbreak included a slight shriveling and sunken appearance at the interface of healthy and necrotic tissue. This transition zone, on removal of bark to expose phloem tissue, revealed a moist abnormal reddish brown coloration extending $\approx 5$ to 10 $\mathrm{mm}$ toward the shoot apex. The necrotic portion of the shoot exhibited dry, or drying, light brown phloem tissue over dry, or drying, xylem. All shoots exhibiting either SpSDM or SuSDM possessed peduncles from the previous year's fruit cluster; thus, the maladies were not exhibited on previousseason vegetative shoots. On some shoots/ branches exhibiting SuSDM, dieback ended at the branch point of lateral shoots or at limb branch points. Identification of the inception of the SDMs, as to whether occurrence was soon after onset of fall dormancy or during late winter, was not obvious and remains unknown. Necrotic lesions were poorly defined and bark death was not apparent until within a couple weeks before bud swelling in early spring; the SDM-associated canker interface was apparent on removal of shoot bark basipetal to attached peduncles.

'Mohawk', 'Cherokee', and 'Success' cultivars displayed especially severe dieback (Table 1) during springs of growing seasons when trees were in the "off" phase (i.e., light crop loads) of their alternate bearing cycles (i.e., "on" during the preceding year) (Table 1). All three cultivars are inherently very prolific; hence, it is possible that such cultivars are more likely to exhibit dieback problems than are relatively nonprolific cultivars. The newly developing foliar canopy of such trees was relatively weak in appearance compared with trees possessing lighter crop loads the preceding growing season. Leaves

Table 1. Percentage of previous season reproductive shoots, from various pecan cultivars exhibiting the SpSDM just before budbreak and the consequent apparent progression of the dieback malady to become SuSDM by early summer.

\begin{tabular}{|c|c|c|c|c|}
\hline \multirow[b]{2}{*}{ Cultivar } & \multicolumn{2}{|c|}{ March-SpSDM ${ }^{z}$} & \multicolumn{2}{|c|}{ June-SuSDM ${ }^{y}$} \\
\hline & Dieback (\%) & Dieback $(\mathrm{cm})$ & Dieback $(\mathrm{cm})$ & Age of wood (years) \\
\hline Cape Fear & 2 & 2.5 & 30.2 & 2 \\
\hline Cherokee & 48 & 7.4 & 33.4 & 2 \\
\hline Desirable & 13 & 2.5 & 41.7 & 2 \\
\hline Elliott & 24 & 7.4 & 33.6 & 2 \\
\hline Mahan & 6 & 2.5 & 22.1 & 2 \\
\hline Mohawk & 48 & 4.9 & 22.4 & 2 \\
\hline Moneymaker & 10 & 2.5 & 22.1 & 2 \\
\hline Moore & 26 & 8.7 & 34.8 & 2 \\
\hline Pawnee & 11 & 2.5 & 23.1 & 2 \\
\hline Schley & 8 & 3.1 & 43.8 & 4 \\
\hline Stuart & 7 & 2.5 & 34.1 & 4 \\
\hline Success & 35 & 8.0 & 33.1 & 3 \\
\hline Western Sch. & 10 & 9.8 & 30.8 & 3 \\
\hline Wichita & 14 & 2.5 & 41.7 & 2 \\
\hline
\end{tabular}

${ }^{\mathrm{z}}$ One hundred shoots with peduncles at the terminal were randomly collected and percentage of dieback assessed. Length of dieback measured from the base of the peduncle. Dieback occurred primarily on 1year-old wood.

${ }^{y}$ Fifty shoots with dieback symptoms per cultivar were collected during June and the length of dieback measured from the base of the peduncle.

${ }^{\mathrm{x}}$ Age (i.e., years) of shoot structures exhibiting dieback. 
not only appeared smaller than normal on such trees, but were slightly chlorotic compared with foliage of lighter crop-load trees. The incidence of SpSDM varied among cultivars before budbreak, ranging from $2 \%$

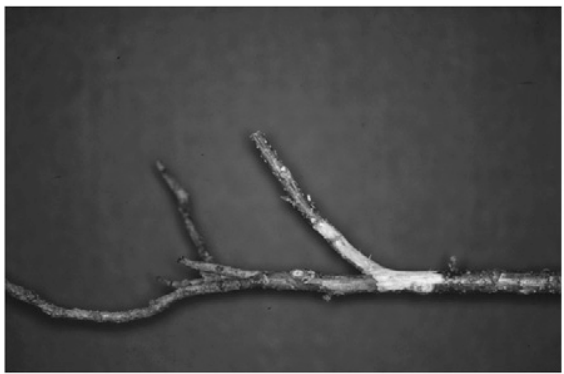

Fig. 1. A 'Moneymaker' pecan shoot exhibiting the spring shoot dieback malady (SpSDM). Note that the necrotic zone of the shoot progressed basipetally from 1-year-old shoots into the 2year-old shoot zone with a pronounced demarcation between symptomatic and healthy tissue. Although not shown here, the infection progressed from an attached peduncle that supported the previous year's fruit. to $48 \%$, and also varied among trees of the same cultivar (Table 1). Before budbreak, shoot dieback was usually less than $10 \mathrm{~cm}$ and appeared on 1-year-old wood (i.e., previous-season shoots), but in some instances measured 15 to $25 \mathrm{~cm}$ and extended into 2-year-old wood (data not presented). During early June, SpSDM developed on branches of all cultivars, extending an average of $33 \mathrm{~cm}$ into 2-, 3-, and 4-year-old wood.

Winter temperatures during the test period were relatively mild and within $\pm 2{ }^{\circ} \mathrm{C}$ of the 22-year averages; thus, there was no obvious likelihood of damage resulting from winter cold. Additionally, an examination of symptomatic shoots did not reveal evidence of damage by stem girdling or boring insects.

Relationship of fungi to spring shoot dieback malady. The dominating fungus isolated from symptomatic SpSDM shoot segments, regardless of cultivar, produced a concentric light gray colony on PDA at $24{ }^{\circ} \mathrm{C}$ (Table 2). Black conidiomata formed throughout the mycelial mat as the colony reached the edge of petri plates within $\approx 6$ to $8 \mathrm{~d}$ and produced biguttulate aseptate

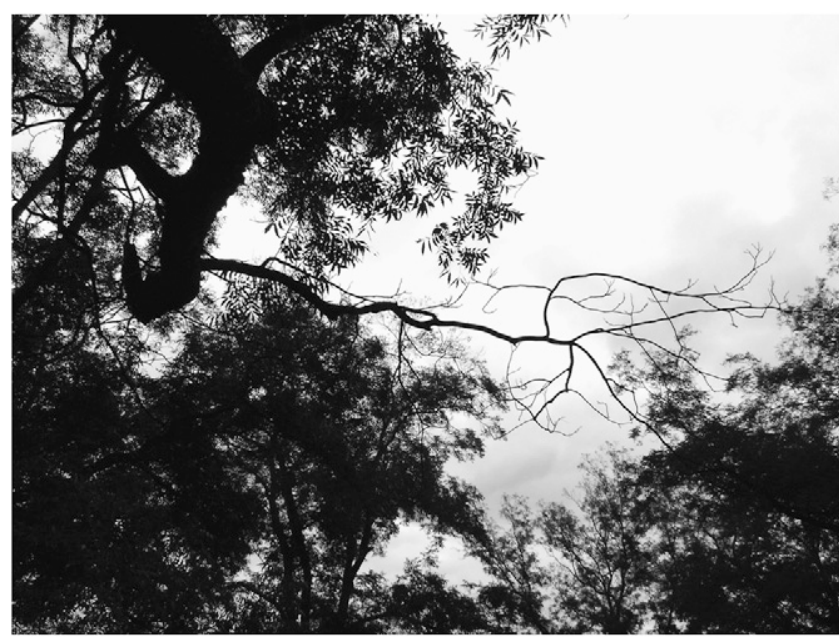

Fig. 2. A 'Moneymaker' pecan shoot exhibiting the summer shoot dieback malady (SuSDM). Note that the dead shoot network is comprised of shoot structures up to $\approx 10$ years old. The foliage, and its supporting vascular system suddenly dies in early to late spring and abscises by early fall to give barren dead branch systems.

Table 2. Isolation frequency of fungi from shoots of 14 pecan cultivars exhibiting the SpSDM and SuSDMs.

\begin{tabular}{lccc}
\hline & & Isolation frequency (\%) & \\
\cline { 2 - 4 } Fungi isolated & SpSDM-March & SuSDM-June & Healthy \\
\hline Phomopsis sp. & 92 & 95 & 17 \\
Alternaria spp. & 9 & 7 & 15 \\
Botryosphaeria spp. $^{\mathrm{y}}$ & 5 & 6 & 0 \\
Epicoccum spp. & 9 & 3 & 4 \\
Fusarium spp. & 2 & 10 & 5 \\
Glomerella cingulata & 2 & 5 & 0 \\
Penicillium spp. & 2 & 4 & 3 \\
Pestalotia spp. & 8 & 9 & 3 \\
Phoma spp. & 2 & 1 & 10 \\
\hline
\end{tabular}

${ }^{\mathrm{z}}$ Data are the mean of samples taken over two growing seasons. Means represent 100 shoots exhibiting dieback malady symptoms for each of 14 cultivars. Healthy specimens were collected from 50 asymptomatic shoots of each cultivar in late March during the time of the SpSDM episode.

${ }^{\mathrm{y}}$ Botryosphaeria dothidea and B. obtusa were the two species isolated.

$\mathrm{SpSDM}=$ spring shoot dieback malady; SuSDM = summer shoot dieback malady.

$\alpha$-conidia (6.8 to $9.0 \mu \mathrm{m} \times 2.5$ to $3.8 \mu \mathrm{m}$ ). The USDA-ARS Systematic Botany and Mycology Laboratory, Beltsville, MD, identified this fungus as a species of Phomopsis. This species was identified as being different from the Phomopsis causing peach dieback in Georgia (Uddin et al., 1997), although the biguttulate aseptate $\alpha$-conidia appeared morphologically identical.

The isolation frequency of organisms from shoots of pecan cultivars was similar over 2 years of study (Table 2). Phomopsis sp. was consistently isolated at high frequencies, $92 \%$ or greater, for each of two evaluation seasons. Isolation frequencies for all other fungi, including species of Alternaria, Botryosphaeria, Epicoccum, Fusarium, Glomerella, Penicillium, Pestalotiopsis, and Phoma, were low (10\% or less) for both years of study. Glomerella cingulata, a leaf and fruit pathogen of pecan (Latham et al., 1995; Rand, 1914), was isolated at low frequency. Phomopsis spp. was isolated from $17 \%$ of healthy, or asymptomatic, shoots with all other organisms isolated at similar frequencies from apparently healthy tissue like with symptomatic tissue during that period (Table 1). It is noteworthy that the presence of Phomopsis sp. in apparently healthy tissue does not necessarily trigger visible SDM symptoms.

In the case of the SpSDM form, Phomopsis sp. is typically present at high frequency $(75 \%$ to $100 \%)$ in symptomatic shoots as compared with Botryosphaeria spp. being at low frequency (i.e., $22 \%$ or less with one exception of $75 \%$ ) (Table 3). Specific cultivars exhibited a range of isolation frequencies for Phomopsis sp., ranging from $76 \%$ for 'Western Schley' to $100 \%$ for 'Cape Fear', 'Desirable', 'Moore', 'Mohawk', and 'Success' (in June of the first year) and 100\% for 'Western Schley', 'Schley', 'Mahan', 'Elliott', and 'Cape Fear' during the spring of the second year. A similar relationship exists in shoot samples taken during June of both years with frequency of isolation of Phomopsis sp. being far more prevalent in symptomatic shoots than that of Botryosphaeria spp. Thus, there is a strong linkage between SuSDM and Phomopsis sp. and a relatively weak relationship with Botryosphaeria spp.

In the case of the SuSDM form, symptoms occurred on all sampled cultivars with $\mathrm{Pho}$ mopsis sp. isolated from the vast majority of sampled shoots at a frequency of $50 \%$ to $100 \%$ with most cultivars being $70 \%$ to $100 \%$ (Table 4). Symptomatic shoots also contained Botryosphaeria spp. at a frequency typically $0 \%$ to $40 \%$. Symptoms of this summer dieback differed from that seen in early spring in that dead leaves and fruit arising from the summer dieback remained firmly attached to dead shoots. The leaves were light brown and had the appearance of being scorched by high temperature or by desiccation. Although both Phomopsis sp. and Botryosphaeria spp. might potentially contribute to the SuSDM form, it appears that Phomopsis sp. is more closely linked to the malady. 
Table 3. Isolation frequency of Phomopsis sp. and Botryosphaeria spp. from shoots of 14 pecan cultivars exhibiting SpSDM symptoms.

\begin{tabular}{|c|c|c|c|c|c|c|}
\hline \multirow[b]{3}{*}{ Cultivar } & \multicolumn{6}{|c|}{ Isolation frequency $(\%)$} \\
\hline & \multicolumn{3}{|c|}{ Phomopsis sp. } & \multicolumn{3}{|c|}{ Botryosphaeria spp. } \\
\hline & $\begin{array}{l}\text { March } \\
\text { first } \mathrm{yr}^{\mathrm{z}}\end{array}$ & $\begin{array}{c}\text { March } \\
\text { second } \mathrm{yr}^{\mathrm{z}}\end{array}$ & $\begin{array}{c}\text { June } \\
\text { first } \mathrm{yr}^{\mathrm{y}}\end{array}$ & $\begin{array}{l}\text { March } \\
\text { first } \mathrm{yr}^{\mathrm{z}}\end{array}$ & $\begin{array}{c}\text { March } \\
\text { second } \mathrm{yr}^{\mathrm{z}}\end{array}$ & $\begin{array}{c}\text { June } \\
\text { second } \mathrm{yr}^{\mathrm{y}}\end{array}$ \\
\hline Cape Fear & 100 & 100 & 98 & 0 & 0 & 6 \\
\hline Cherokee & 98 & 94 & 94 & 2 & 6 & 8 \\
\hline Desirable & 92 & 79 & 100 & 8 & 0 & 4 \\
\hline Elliott & 96 & 100 & 96 & 6 & 0 & 2 \\
\hline Mahan & 96 & 100 & 92 & 2 & 0 & 4 \\
\hline Mohawk & 100 & 91 & 100 & 0 & 0 & 0 \\
\hline Moneymaker & 78 & 92 & 100 & 22 & 8 & 2 \\
\hline Moore & 100 & 86 & 98 & 2 & 5 & 2 \\
\hline Pawnee & 82 & 33 & 78 & 18 & 75 & 44 \\
\hline Schley & 89 & 100 & 90 & 2 & 0 & 4 \\
\hline Stuart & 96 & 75 & 88 & 2 & 12 & 2 \\
\hline Success & 100 & 98 & 97 & 8 & 0 & 2 \\
\hline Western Schley & 76 & 100 & 100 & 8 & 0 & 2 \\
\hline Wichita & - & 87 & 94 & - & 19 & 8 \\
\hline
\end{tabular}

${ }^{\mathrm{z}}$ One hundred shoots per cultivar were randomly collected before budbreak and only those having dieback symptoms were used for isolations.

${ }^{y}$ Fifty shoots having dieback symptoms per cultivar were used for the isolations.

$\mathrm{SpSDM}=$ spring shoot dieback malady.

Table 4. Isolation frequency of Phomopsis sp. and Botryosphaeria spp. from shoots/limbs exhibiting the SuSDM during late August.

\begin{tabular}{lcc}
\hline & \multicolumn{2}{c}{ Frequency of isolation $(\%)^{\mathrm{z}}$} \\
\cline { 2 - 3 } Cultivar & Phomopsis & $\begin{array}{c}\text { Botryosphaeria } \\
\text { sp. }\end{array}$ \\
\hline Cherokee & 70 & 20 \\
Cheyenne & 100 & 40 \\
Desirable & 100 & 30 \\
Farley & 90 & 0 \\
Moneymaker & 60 & 40 \\
Moore & 70 & 10 \\
Schley & 70 & 10 \\
Stuart & 50 & 10 \\
Wichita & 90 & 40 \\
\hline
\end{tabular}

${ }^{\mathrm{z} P h o m o p s i s ~ s p . ~ a n d ~ B o t r y o s p h a e r i a ~ s p p . ~ w e r e ~}$ isolated concurrently from certain shoot samples. SuSDM = summer shoot dieback malady.

Influence of stress. The incidence of the SpSDM on shoots of 'Cherokee' trees was influenced by stress treatments in that trees under relatively severe stress also exhibited a greater percentage of 1-year-old shoots exhibiting SpSDM symptoms (Table 5). Although $12 \%$ or greater of all shoots exhibited the SpSDM, regardless of developmental state or tree stress treatment, trees experiencing treatments designed to impose relatively severe stress conditions exhibited $\approx 2$-fold ( $29 \%$ versus $12 \%$ to $15 \%$ ) greater frequency of SpSDM than did treatments imposing lesser degrees of stress. Thus, although SpSDM appears capable of occurring regardless of stress level, incidence appears greatest in highly stressed trees.

When isolations were taken from the symptomatic dying zone of SpSDM-affected shoots the spring after the imposition of the various stress treatments, the same nine genera of fungi were present as found in the previously described survey of pathogens isolated from SpSDM symptomatic shoots of 14 cultivars (Table 6). The predominant isolated fungus was Phomopsis sp., occurring in $83 \%$ or greater of symptomatic shoots.
Although six to eight other fungal genera were detected in symptomatic shoots, isolation frequency of these genera was typically $2 \%$ to $13 \%$.

\section{Discussion}

The SpSDM is typified by death of the apical portion of 1-year-old shoots with the necrotic zone being contiguous with the residual peduncle, or peduncle attachment point, from the previous year's fruit cluster. This malady can also extend into shoots 1 year of age or older to kill small branches (Fig. 1). The SuSDM form is most apparent during summer; typified by sudden death of canopy structures, ranging from small branches to major limbs, predominantly within relatively shady canopy zones, with foliage of affected shoots or limbs dying suddenly, displaying a uniform light brown scorched appearance while remaining firmly attached to the parent shoot. This malady can kill relatively large branch systems, some of which are often growing in full sunlight (Fig. 2 ). Both SDM maladies display a narrow band of abnormal tissue at the healthy necrotic interface of affected shoots and limbs with the band moving basipetally as the infection progresses.

Early spring shoot death resulting from winter cold injury is influenced by tree stress as a consequence of the previous growing season and typically affects shoots that were in either reproductive or vegetative modes during the previous growing season (Wood, 1986). The absence of severe winter cold during the time of the present study, plus a near absence of SpSDM being exhibited by shoots vegetative during the previous growing season, and relative high incidence of SpSDM in shoots bearing fruit the previous growing season is evidence that this shoot dieback was not the result of cold injury. Additionally, observations by Matz (1918) and Cole (1968) of a likely linkage between
Table 5. Relative incidence of SpSDM-affected shoots in 'Cherokee' trees the spring after imposition of fruit-associated stress treatments the previous growing season.

Relative stress

treatment ${ }^{\mathrm{z}} \quad$ Shoot dieback (\%)

Severe $29 \mathrm{a}^{\mathrm{y}}$

Moderate $12 \mathrm{~b}$

Light $15 \mathrm{~b}$

Minimal

$14 \mathrm{~b}$

${ }^{\text {zSevere }}=$ heavy crop load of large fruit; moderate $=$ heavy crop load of small fruit; light $=$ small crop load of large fruit; minimal $=$ small crop load of small fruit.

${ }^{\mathrm{y}}$ Means with different letters are significantly different at $P=0.05$ using Tukey's honestly significant difference test.

SpSDM $=$ spring shoot dieback malady.

Botryosphaeria spp. and putative cold injury shoot dieback is evidence that one or more fungi are likely involved in certain forms of spring shoot death. In the present study, Botryosphaeria spp. was not detected at high frequency in symptomatic shoots, although it has been reported to cause similar shoot dieback maladies in pistachio trees (Pistacia vera; Ahimera et al., 2003; Michailides, 2002; Ntahimpera et al., 2002). Glomerella cingulata [a pathogen causing fungal leaf scorch and shuck disease in pecan (Latham et al., 1995; Rand, 1914)] also does not appear to cause the SDMs. The presence of a Phomopsis sp. in symptomatic zones of shoots indicates that this fungus is most likely the primary causal biological agent of both forms of SDM. The several other fungi found occasionally in symptomatic shoots appear to be saprobic fungi colonizing shoot tissues already killed by Phomopsis sp. and/or Botryosphaeria spp.

Phomopsis is a large, coelomycetous genus that includes over 1000 species described primarily on the basis of their plant host (Uecker, 1988). Phomopsis sp. was nearly always detected in symptomatic pecan tissue of the present study (and failure to detect does not necessarily mean absence). The putative association between Phomopsis and twig dieback in pecan as report by Alfieri et al. (1984), Reilly (1991), and Reilly and Reynolds (1994) is supported by the present study.

Previous observations by the authors are such that SpSDM is most severe in early springs after relatively heavy nut crops during the previous year, whereas SuSDM is most severe in summers after heavy previousyear nut crops and wet spring weather. The severe dieback of shoots occurring in Georgia during the spring of 2002, after 4 years of drought (Sparks, 2003), might well have been the result of Phomopsis sp. attacking weakened shoots, similar to that of a Phomopsis shoot dieback reported for stressed pistachio (Michailides, 2002), black alder (Alnus glutinosa; Moricca, 2002), lingonberry (Vaccinium vitis-idaea; Farr et al., 2002b), blueberry (Vaccinium corymbosum), cranberry ( $V$. macrocarpon), grape (Vitis vinifera; Phillips, 1998), and several Rosacea species (Farr et al., 1999, 2002a). 
Table 6. Isolation frequency of fungi from shoots of 'Cherokee' pecan exhibiting SpSDM as a function of different degrees of tree stress.

\begin{tabular}{lcccr}
\hline & \multicolumn{4}{c}{ Frequency of isolation $(\%)^{\mathrm{z}}$} \\
\cline { 2 - 5 } Fungi isolated & Severe $^{\mathrm{y}}$ & Moderate & Light & Minimal \\
\hline Alternaria spp. & 3 & 7 & 7 & 3 \\
Botryosphaeria spp. & 10 & 10 & 8 & 13 \\
Epicoccum spp. & 2 & 5 & 7 & 8 \\
Fusarium spp. & 8 & 2 & 2 & 8 \\
Glomerella cingulata & 2 & 2 & 2 & 0 \\
Penicillium spp. & 0 & 2 & 2 & 2 \\
Pestalotiopsis spp. & 2 & 0 & 0 & 2 \\
Phoma spp. & 0 & 5 & 5 & 5 \\
Phomopsis sp. & 92 & 83 & 83 & 88 \\
\hline
\end{tabular}

${ }^{\mathrm{z}}$ Five isolations, from separate shoots with spring shoot dieback symptoms, were preformed on each of the six trees in each treatment.

${ }^{\mathrm{y}}$ Severe $=$ heavy crop load of large fruit; moderate $=$ heavy crop load of small fruit; light $=$ small crop load of large fruit; minimal = small crop load of small fruit.

SpSDM $=$ spring shoot dieback malady.

The increased frequency of SpSDM exhibited by "severely" stressed trees indicates that the ability of one or more factors causing this dieback malady is influenced by the degree of physiological stress imposed on shoot tissues. The observed presence of Phomopsis sp. in symptomatic tissues of nearly all affected shoots identifies a strong linkage between Phomopsis sp. and SpSDM; however, it does not prove a cause-and-effect relationship. Such proof awaits completion of Koch's postulates. In the present study, Phomopsis sp. was found in abundance in almost all symptomatic tissue and was successfully grown in pure culture; nevertheless, the ability of cultured Phomopsis sp. to cause dieback in inoculated shoots and its reisolation and identification merit further study. This linkage of Phomopsis sp. to SpSDM was apparent for all 14 cultivars surveyed, indicating that the putative pathogen is probably widely distributed among orchards and might be capable of causing major damage to tree canopies under opportune conditions. The genotypic variability observed for both SDM forms might reflect variation in resistance to the dieback maladies or might be more directly related to stresses arising as a consequence of typically heavy cropping of these cultivars.

\section{Conclusions}

These data and observations are consistent with the hypothesis that fungal pathogens can kill shoots of pecan trees when sufficiently stressed during the previous growing season and that the primary pathogen is Phomopsis sp. but with Botryosphaeria spp. also potentially contributing. The primary stress factor appears to be associated with fruiting. Although it is possible that one or more of the other fungi isolated in symptomatic shoots contributes to these shoot dieback maladies, it may be that they only do so in combination with Phomopsis sp. and/ or Botryosphaeria spp. This linkage of Pho- mopsis sp. with death of young shoots near time of budbreak in early spring may account for the paradoxical observation of what appears to be shoot dieback resulting from winter or spring cold yet with insufficiently low temperatures to cause such damage. The tight linkage of these two SDMs in association with peduncles from previous-season fruit clusters indicates that peduncles harbor pathogenic fungi that infect and potentially kill healthy mother shoots and, in certain cases, the older supporting limb network. Thus, these fungi are potentially relevant to development of management strategies for maximizing canopy health, leaf area, and nutmeat yield and quality. There appears to be merit for follow-up study regarding the ability of Phomopsis sp. and/or Botryosphaeria spp. to trigger both spring and summer forms of shoot dieback and how these fungi interact with factors stressing trees to trigger sudden shoot death.

\section{Literature Cited}

Ahimera, N., G.F. Driever, and T.J. Michailides. 2003. Relationships among propagule numbers of Botryophaeria dothides, latent infections, and severity of panicle and shoot blight in pistachio orchards. Plant Dis. 87:846-853.

Alfieri, S.A., K.R. Langdon, C. Wehlburg, and J.W. Kimbrough. 1984. Index of plant diseases in Florida. Florida Dept. of Agriculture and Consumer Services, Div. of Plant Industries Bull. No. 11.

Cole, J.R. 1968. Dieback affecting pecan trees in southwest Georgia and north Florida. Plant Disease Reporter 52:947-949.

Ellis, H.C., J. Hadden, T.F. Crocker, and S. Brown. 1991. Georgia pecan spray guide. Univ. of GA Coop. Exten. Serv. Bull. No. 841.

Farr, D.F., L.A. Castlebury, and R.A. PardoSchultheiss. 1999. Phomopsis amygdale causes peach shoot blight of cultivated peach trees in the southeastern United States. Mycologia 91:1008-1015.

Farr, D.F., L.A. Castlebury, and A.Y. Rossman. 2002a. Morphological and molecular characterization of Phomopsis vaccinii and additional isolates of Phomopsis from blueberry and cranberry in the eastern United States. Mycologia 94:494-504.

Farr, D.F., L.A. Castlebury, A.Y. Rossman, and M.L. Putnam. 2002b. A new species of Phomopsis causing twig dieback of Vaccinium vitis-idaea (lingonberry). Mycol. Res. 106: 745-752.

Latham, A.J., K.L. Bowen, and H.L. Campbell. 1995. Occurrence of Glomerella cingulata in pecan nut shucks and its association with fungal leaf scorch. Plant Dis. 79:182-185.

Matz, J. 1918. Pecan dieback. Fla. Agr. Exp. Sta. Bul. 147. p. 141-143.

Michailides, T.J. 2002. Phomopsis blight, p. 64-75. In: Teviotdale, B.L., T.J. Michailides, and J.W. Pscheidt (eds.). Compendium of nut crop diseases in temperate zones. APS Press, St. Paul, $\mathrm{MN}$.

Moricca, S. 2002. Phomopsis alnea, the cause of dieback of black alder in Italy. Plant Pathol. 51:755-764.

Ntahimpera, N., G.F. Driever, D. Felts, D.P. Morgan, and T.J. Michailides. 2002. Dynamics and pattern of latent infection caused by Botryosphaeria dothidea on pistachio buds. Plant Dis. 86:282-287.

Phillips, A.J.L. 1998. Botryosphaeria dothidea and other fungi associated with excoriose and dieback of grapevines in Portugal. J. Phytopathol. 146:327-332.

Rand, F.V. 1914. Some diseases of pecans. J. Agr. Res. 1:303-344.

Reilly, C.C. 1991. Considerations in the management of pecan diseases, p. 16-21. In: Wood, B. and J. Payne (eds.). Pecan husbandry: Challenges and opportunities, First National Pecan Workshop, Unicoi, GA. USDA-ARS, ARS-96.

Reilly, C.C. and K.L. Reynolds. 1994. Fungi involved in fungal leaf scorch and the shuck disease complex of pecan. Southeastern Pecan Growers Association Proceedings 87:129142.

Sparks, D. 2003. Pecan tree dieback following 1999-2002 drought associated with September rainfall. J. Amer. Pomological Soc. 57:142-146.

Sparks, D., W. Reid, I.E. Yates, M.W. Smith, and T.G. Stevenson. 1995. Fruiting stress induces shuck decline and premature germination in pecan. J. Amer. Soc. Hort. Sci. 120:3-4.

Uddin, W., K.L. Stevenson, and R.A. PardoSchultheiss. 1997. Pathogenicity of a species of Phomopsis causing a shoot blight on peach in Georgia and evaluation of possible infection courts. Plant Dis. 81:983-989.

Uecker, F.A. 1988. A world list of Phomopsis names with notes on nomenclature, morphology, and biology. Mycol. Mem. 13:1-231.

Wood, B.W. 1986. Cold injury susceptibility of pecan as influenced by cultivar, carbohydrates, and crop level. HortScience 21:285-286.

Wood, B.W. 1995. Relationship of reproductive and vegetative characteristics of pecan to previous-season fruit development and postripening foliation. J. Amer. Soc. Hort. Sci. 120: 635-642.

Worley, R.E. 1979a. Pecan yield, quality, nutlet set and spring growth as a response to time of fall defoliation. J. Amer. Soc. Hort. Sci. 104:192-194

Worley, R.E. 1979b. Fall defoliation date and seasonal carbohydrate concentration of pecan wood tissue. J. Amer. Soc. Hort. Sci. 104: 195-199. 